Article

\title{
Dynamic Measurement of Water Use Level Based on SBM-DEA Model and Its Matching Characteristics with Economic and Social Development: A Case Study of the Yellow River Basin, China
}

\author{
Zhizhuo Zhang ${ }^{1}$, Qiting Zuo ${ }^{1,2,3, *}$, Long Jiang ${ }^{1}$, Junxia Ma ${ }^{1,2} \mathbb{D}$, Weiling Zhao ${ }^{4}$ and Hongbin Cao ${ }^{4}$ \\ 1 School of Water Conservancy Engineering, Zhengzhou University, Zhengzhou 450001, China; \\ zhangzhizhuozzu@163.com (Z.Z.); jianglong328@163.com (L.J.); majx@zzu.edu.cn (J.M.) \\ 2 Henan International Joint Laboratory of Water Cycle Simulation and Environmental Protection, \\ Zhengzhou 450001, China \\ 3 Yellow River Institute for Ecological Protection \& Regional Coordinated Development, Zhengzhou University, \\ Zhengzhou 450001, China \\ 4 Northern Henan Water Conservancy Project Management Bureau, Xinxiang 453000, China; \\ ywzdsxd@126.com (W.Z.); caohongbin@hnsl.gov.cn (H.C.) \\ * Correspondence: Zuoqt@zzu.edu.cn
}

check for

updates

Citation: Zhang, Z.; Zuo, Q.; Jiang, L.; Ma, J.; Zhao, W.; Cao, H. Dynamic Measurement of Water Use Level Based on SBM-DEA Model and Its Matching Characteristics with Economic and Social Development: A Case Study of the Yellow River Basin, China. Water 2022, 14, 399. https://doi.org/10.3390/w14030399 Academic Editor: Antonio Lo Porto

Received: 15 December 2021

Accepted: 25 January 2022

Published: 28 January 2022

Publisher's Note: MDPI stays neutral with regard to jurisdictional claims in published maps and institutional affiliations.

Copyright: (C) 2022 by the authors. Licensee MDPI, Basel, Switzerland. This article is an open access article distributed under the terms and conditions of the Creative Commons Attribution (CC BY) license (https:// creativecommons.org/licenses/by/ $4.0 /)$.

\begin{abstract}
Enhancing the level of water use and alleviating the constraints of water shortage on economic and social development are powerful supports to realize the harmonious balance of water and economic society. In this study, the data envelopment analysis (DEA) window analysis method is applied to the study of water use level, and the SBM-DEA model (slack based measure, SBM) is combined to explore the spatial and temporal evolution characteristics of composite water use index (CWUI) in nine provinces from 2012 to 2018. The Malmquist index model is used to decompose the intrinsic causes of total factor productivity (TFP) changes, and the spatial matching degree calculation method is applied to study the matching degree between CWUI and economic and social development levels (E-SDL). The results showed that: (1) the overall trend of CWUI in the nine provinces from 2012 to 2018 was increasing, with significant spatial variability in water use levels; (2) the improvement of TFP of water in the nine provinces was mainly driven by technological change (TC), and the main factor limiting the improvement of TFP of water was technical efficiency change (EC); (3) E-SDL of the nine provinces showed an increasing trend, with the spatial distribution characteristics of decreasing E-SDL of the downstream, midstream and upstream provinces in sequence; (4) the degree of matching between CWUI and E-SDL shows strong regional differences, with different types of matching.
\end{abstract}

Keywords: water use level; SBM-DEA model; window-DEA model; economic and social development; matching degree; yellow river basin

\section{Introduction}

UNESCO (United Nations Educational, Scientific and Cultural Organization) defines the water resource as a source of water of a certain quality and quantity that is available and potentially available to meet the utilization needs of a site in the long term [1]. Water resources are the basic support for economic and social development, as well as a necessary guarantee for the construction of ecological civilization [2]. Since the 21st century, a green, coordinated, and sustainable water resource utilization model has gradually become a hot spot of concern for countries around the world [3]. The United Nations Sustainable Development Summit in 2015 released the 2030 Agenda for Sustainable Development, which identifies 17 Sustainable Development Goals (SDGs) covering economic, social, resource, and ecological dimensions [4]. It is internationally recognized that an important part of achieving SDGs is to conduct a comprehensive and in-depth exploration of water 
security [5], water and soil resource use efficiency [6-8], and sustainable energy use [9] in order to break the excessive dependence on energy resources for economic and social development. At present, China is facing huge pressure on water resources. The intertwining problems of water demand and supply [10], water environment pollution [11], and water ecology deterioration [12] have formed a serious water resource challenge, which seriously hinders the realization of sustainable development. In 2012, the Strictest Water Resources Management System was issued by the Chinese government [13], which issued three rules for total water use, water use efficiency, and state of water function zones. The Yellow River is called the mother river of China. It is also one of the seven significant rivers in China. The Yellow River basin is an important ecological barrier in northern China [14]. In 2019, The Chinese government promoted conservation and intensive use of water resources as an important strategy for the future development of the Yellow River basin [15]. The key way to tackle the increasingly complex water resource issues in the Yellow River Basin and even in China is to achieve efficient utilization of water resources and ensure stable social development and economic progress with minimal resource input. Thus, it is clear that quantitative research on regional water use level and exploration of the matching relationship between economic and social development and resource utilization levels are of strategic importance for the sustainable and healthy economic and social development of regions, provinces, and even countries.

Water use level is a key metric reflecting the effective exploitation, management, and utilization of water resources. As the contradiction between economic and social development and water shortage is becoming more and more prominent, many scholars have conducted comprehensive research on water use levels in recent years and gradually formed a complete theoretical and methodological system. Different research fields have different definitions of water use levels. At present, common research on water use levels can be broadly divided into two scales, macro and micro. Micro-scale studies mainly focus on the moisture utilization capacity of different crops [16,17] and farms [18], as well as agricultural irrigation efficiency. The main methods include the life cycle approach [19], water production function [20], etc. Micro-scale water use efficiency studies focus on exploring the efficiency of water and energy conversion during plant production. Moreover, in such studies, water use efficiency (WUE) is the most common indicator to characterize the level of water use. It can be simply summarized as dry matter mass produced per unit of water consumed by plant growth. The other category is macro-scale. This type of research focuses on exploring the overall water use levels of different regions and industries. This study proposes a new index, CWUI (composite water use index), to represent the level of water use. Referring to such studies, the definition of CWUI can be simply summarized as: macroscopically, the ability of a region or industry to obtain economic output through the integrated use of water and related inputs. The main methods for water use level studies at the macro scale include single-indicator assessment [21], multi-indicator integrated assessment [22], data envelopment analysis (DEA) model [23], stochastic frontier approach (SFA) model [24], and genetic projection tracing model [25], etc. Among them, the DEA model integrates the relevant knowledge of operations research, economics, and management science and can evaluate the relative effectiveness of comparable units of the same type using linear programming. Since this method does not require any assumptions, it has reflected its unique advantages in water resources level research, and a large number of high-quality research results have emerged. In terms of research scales, involving different scales includes national [26], provincial [27], and urban [28]. For example, Ibrahim et al. [26] measured the efficiency of the water-energy-land-food nexus in Organization for Economic Cooperation and Development (OECD) countries using a non-parametric benchmark ranking model derived from a DEA approach. Lu et al. [28] evaluated the spatial and temporal change characteristics of agricultural water use level and its related factors in northwest China using the combination of super-efficient DEA model. In terms of research areas, the water use level of different industries (agriculture [29], industry [30,31]) and the regional integrated water use efficiency [32] were covered. For example, Yang et al. [31], used a 
DEA model to assess the water use level of the three major industries in 30 provinces in mainland China. In studies on DEA models, traditional CCR and BCC models [33], super-efficient DEA models [34], SBM-DEA models [27,30,35], Malmquist models [24,36], etc., are involved. For example, Bai et al. [36], constructed a non-radial method based on the theory of Malmquist to dynamically measure changes in water use level of the Bohai Bay urban cluster in China. In recent years, with the gradual development of the green development concept. It is worth noting that DEA models considering non-expected output have started to appear more often in resource and energy use level studies. For example, Yang et al. [30] chose a non-expected output SBM model to measure the industrial water use level in mainland China. It can be found that the DEA method was widely applied in the field of water resources. The above high-quality research results provided a solid basis for the smooth development of subsequent studies.

Economic and social development and the level of resource and energy utilization are inextricably linked, especially under the dual effect of intensifying climate change and the impact of human activities. Whether the level of resource and energy utilization can match the level of economic and social development has become an important indicator to measure the sustainable development capability of the region. With the further implementation of sustainable development policies, the relationship between the level of resource and energy use and sustainable development has gradually become a hot issue of global concern. In this context, many scholars have adopted various methods to explore the relationship between the two. The subjects of this kind of study are mainly related to energy consumption [37-39], pollution emissions [40], land resource use [41,42], etc. For example, Sarkodie et al. [38] examined the effects of energy consumption on GHG emissions using U-test estimation methods and non-additive fixed effects panel quantile regression. On World Water Day, March 22, 2021, UNESCO released the World Water Development Report 2021 [43], which focuses on "the value of water" to explain the important role of water resources in economic and social development in different dimensions. There are not many studies on the relationship between water resources utilization and economic and social development, but some scholars conducted relevant studies. For example, Sun [44] constructed a system dynamics model to study sustainable water resources utilization considering economic development, and simulated the water resources supply and demand situation from 2005 to 2020 and the changes of future supply and demand gap. The above research results have contributed value in promoting sustainable economic and social development.

After combing through the representative literature in recent years, it can be found that the important results revealed by the above-mentioned studies have greatly promoted the development of the field of water use level and the field of water resources-economic and social relations, and expanded the scope and depth of research in this field. However, there are some shortcomings. For example, most studies on water use levels still use the DEA cross-sectional model to deal with long time series panel data. This defect leads to the comparison of different decision units only within a specific year, and the evolution characteristics of water use level in time series cannot be analyzed, which reduces the reference value of the results to some extent. Meanwhile, some studies used traditional radial DEA models to measure water use levels, which failed to fully consider slack variables [45]. Finally, studies on the matching relationship between water use level and economic and social development in the Yellow River Basin are still relatively lacking.

However, the combination of SBM-DEA model and Window-DEA model can effectively solve the above problems. This study attempts to apply the DEA window analysis method to the study of water use level, combining the SBM-DEA model to explore the spatial and temporal evolution characteristics of water use level in nine provinces in the Yellow River basin. It can realize the dynamic analysis of CWUI under the premise of considering slack variables. On this basis, the Malmquist index model is used to analyze the deep-seated reasons, leading to the variation of total factor productivity of water, and the spatial matching degree calculation method based on series distance is introduced 
for exploring the matching relationship between E-SDL and CWUI. This study aims to achieve the following objectives: (1) apply the SBM-DEA model combined with WindowDEA model to the study of water use level; (2) conduct dynamic evaluation of water use level in nine provinces with consideration of relaxation improvement; (3) clarify the deepseated reasons for the changes in total factor productivity of water in the nine provinces; (4) analyze the matching characteristics between the level of water utilization and the level of economic and social development in the nine provinces under different time scales.

The rest of this study is structured as follows: Part 2 introduces the four main research methods, Part 3 presents an overview of the study area and the selection of relevant indicators, and Part 4 analyzes the spatial and temporal evolution characteristics of CWUI, the changes in TFP of water, and the matching characteristics of CWUI and E-SDL. Part 5 is the conclusion and the outlook for future research.

\section{Methodology}

\subsection{SBM-DEA Model}

The DEA model can be used to evaluate the relative efficiency of different DMUs (decision-making units) through means of a specific mathematical programming model. The basic principle is to determine the production frontier surface with the help of a linear model and to determine the relative efficiency value of each decision unit by comparing the deviation of each decision unit relative to the production frontier surface. DEA models are widely used in efficiency assessment studies because they do not require assumptions about the functional relationships between variables and avoid too much subjectivity. However, the traditional radial DEA model is also partially flawed in that it does not consider slack variables in the efficiency measure of inefficient DMUs. In traditional radial DEA models (e.g., CCR-DEA, BCC-DEA, etc.), the assessment of the degree of DMU inefficiency only includes the proportional change of outputs and inputs. For the ineffective DMU, the gap between its current state and the state of the effective DMU on the production frontier should contain both equal proportional improvement and slack improvement, and the slack improvement part is not reflected in the traditional radial DEA model. Especially when the number of input-output indicators is relatively large, there will be more invalid DMUs, and the traditional radial DEA model loses the function of measuring the slack variables of invalid DMUs, and in such cases, the measurement results are not accurate to a certain extent. The slack variable-based efficiency measurement model (SBM) proposed by Tone [46] incorporated slack variables of input-output indicators into the calculation of decision unit efficiency, which effectively improved the problem of lack of consideration of slack variables in traditional DEA models.

Assuming there are $n$ DMUs, each DMU contains $m$ input $X$ and $q$ output $Y$. The a-th input of the $\mathrm{k}$-th DMU is expressed as $\mathrm{x}_{\mathrm{ak}}(\mathrm{a}=1,2, \ldots, \mathrm{m} ; \mathrm{k}=1,2, \ldots, \mathrm{n})$, the $\mathrm{b}$-th output is expressed as $\mathrm{y}_{\mathrm{bk}}(\mathrm{b}=1,2, \ldots, \mathrm{q} ; \mathrm{k}=1,2, \ldots, \mathrm{n})$, then the input-oriented SBM-DEA model with constant returns to scale can be expressed as [46]:

$$
\begin{array}{cl}
\min \theta= & 1-\frac{1}{m} \sum_{i=1}^{m} s_{i}^{-} / x_{i k} \\
\text { s. t. } & X \lambda+s^{-}=x_{k} \\
& Y \lambda \geqslant y_{k} \\
& \lambda, s^{-} \geqslant 0
\end{array}
$$

In Equation (1), $X_{k}=\left(x_{1 k}, x_{2 k}, \ldots, x_{m k}\right), Y_{k}=\left(y_{1 k}, y_{2 k}, \ldots, y_{q k}\right) ; s^{-}$is the slack variable, i.e., the slack improvement value of the input index; $\theta$ and $\lambda$ are the relative efficiency value and weight of the decision unit respectively, if $\theta \geq 1$, it stands that the DMU is in production frontier and belongs to the effective DMU. 


\subsection{Window-DEA Model}

In most cases, efficiency values need to be dynamically assessed for multiple regions in different years. However, the SBM-DEA model cannot measure the whole panel data directly because the production frontier is different in different years, and the model can only decompose the panel data into cross-sectional data for static measurement separately. Therefore, the efficiency results measured by SBM-DEA model alone are not comparable between years. However, the Window-DEA model, also known as the DEA window analysis method, is a good solution to these problems [47].

The basic principle of DEA window analysis method is that the same decision unit in different years is regarded as multiple independent DMUs to participate in the calculation. Then, a number of reference sets are constructed based on the moving average method to realize the dynamic evaluation of efficiency values under the conditions of multiple decision units and long time series. Through the window analysis, it can meet the need of dynamic comparative analysis of each decision unit in time series. Moreover, the same cross-sectional data are repeatedly involved in the calculation, which can more fully explore the data value and reflect the real level. Thus, the DEA window analysis method is fully applied in the dynamic assessment of efficiency or performance of long time series in many fields. The difference between the Window-DEA model and the SBM-DEA model is only the change of reference set thus the DEA window analysis method can be well combined with the SBM-DEA model.

\subsection{Malmquist Index Model}

In order to analyze the evolution of CWUI in more depth and to explore the deepseated causes of efficiency changes, this study uses the Malmquist index model to explore the changes of TFP of water. Malmquist index is a non-parametric indicator used to dynamically measure the change in TFP of each DMU [48]. Moreover, Färe et al. [49] firstly used the Malmquist index for efficiency research in conjunction with DEA theory and proposed a decomposition method for total factor productivity change factors. $t+1$ period compared to $t$ period productivity change can be decomposed into integrated technical efficiency change (EC) and technical change (TC). TC refers to technological progress, which can also be understood as the forward movement of the production frontier. EC and TC are the two main causes of changes in TFP. Moreover, EC can be decomposed into deeper pure technical efficiency change (PEC) and scale efficiency change (SEC). The decomposition method can be expressed as [49]:

$$
\begin{aligned}
& M I_{t, t+1}=\left[\frac{T F P_{t}\left(x_{t+1}, y_{t+1}\right)}{T F P_{t}\left(x_{t}, y_{t}\right)} \frac{T F P_{t+1}\left(x_{t+1}, y_{t+1}\right)}{T F P_{t+1}\left(x_{t}, y_{t}\right)}\right]^{\frac{1}{2}} \\
& =\frac{T F P_{t+1}\left(x_{t+1}, y_{t+1}\right)}{T F P_{t}\left(x_{t}, y_{t}\right)}\left[\frac{T F P_{t}\left(x_{t}, y_{t}\right)}{T F P_{t+1}\left(x_{t}, y_{t}\right)} \frac{T F P_{t}\left(x_{t+1}, y_{t+1}\right)}{T F P_{t+1}\left(x_{t+1}, y_{t+1}\right)}\right]^{\frac{1}{2}} \\
& =E C_{t, t+1} \times T C_{t, t+1}=P E C_{t, t+1} \times S E C_{t, t+1} \times T C_{t, t+1}
\end{aligned}
$$

In Equation (2), $\mathrm{MI}$ is the Malmquist index, $\mathrm{MI}_{t, t+1}>1$ means that the TFP of water in period $t+1$ has increased compared to period $t ; \mathrm{EC}_{t, t+1}>1$ means that the DMU is closer to the production frontier in period $t+1$ compared to in period $t$, representing an increase in overall technical efficiency; and $\mathrm{TC}_{t, t+1}>1$ means that the production frontier in period $t+1$ has moved forward compared to period $t$, representing technological progress.

In this study, there is a strong link between the SBM-DEA model and the Malmquist index model. The SBM-DEA model measures integrated technical efficiency, and the Malmquist index model measures the rate of change in total factor productivity. The rate of change in TFP is not TFP itself. The Malmquist index model is a nonparametric model that cannot calculate TFP itself but can calculate the rate of change in TFP. The rate of change in TFP is also known as the Malmquist index (MI), and it can be further decomposed into the rate of change of integrated technical efficiency EC and technical progress TC. In efficiency studies involving long time series, the production frontier is constantly moving forward 
and can be understood as technical progress TC. The analysis of technical efficiency using only the SBM-DEA model is incomplete. Therefore, this study uses the Malmquist index model as an effective complement to the SBM-DEA model, and the two models together constitute the quantitative assessment model of water use level in this study.

\subsection{Spatial Matching Degree Calculation Method Based on Series Distance}

The matching degree calculation method based on the distance of the series proposed by Zuo et al. [50] can quantitatively describe the matching degree between different variables. The basic principle of this method is to create a new data series by using the proportion of a value in the series to the total value of the series and then characterize the match according to the ratio of the difference between the values of different variables and the maximum distance in the new data series. In this paper, the methodology is used to quantitatively assess the matching relationship between CWUI and economic and social development level (E-SDL) in nine provinces of the Yellow River Basin. Assuming that the study object contains a total of $\mathrm{N}$ subunits, a quantitative study of the match between two variables, $A_{1}$ and $A_{2}$ is carried out using a spatial matching degree calculation method based on the series distance, which is calculated as follows:

$$
M D_{r}=1-\frac{\left|x_{1}(r)-x_{2}(r)\right|}{\max _{r=1}^{N}\left(x_{1}(r), x_{2}(r)\right)-\min _{r=1}^{N}\left(x_{1}(r), x_{2}(r)\right)}
$$

In Equation (3), $x_{1}(r)=\frac{A_{1}(r)}{\sum_{r=1}^{N} A_{1}(r)}, x_{2}(r)=\frac{A_{2}(r)}{\sum_{r=1}^{N} A_{2}(r)},(r=1,2, \cdots, N) ; \mathrm{MD}_{\mathrm{r}}$ is the degree of the match between the two variables $A_{1}$ and $A_{2}$ in the rth subunits.

It is important to note that Equation (3) only applies to the quantification of the degree of the match when the two variables are positively correlated (i.e., the larger the value of $A_{1}$ and the larger the value of $A_{2}$, the better the match between the two variables). The formula for calculating the degree of the match when the two variables are negatively correlated can be given similarly (i.e., the larger the value of $A_{1}$ and the smaller the value of $A_{2}$, the better the match between the two variables):

$$
M D_{r}=1-\frac{\left|x_{1}(r)+x_{2}(r)-\max _{r=1}^{N}\left(x_{1}(r), x_{2}(r)\right)-\min _{r=1}^{N}\left(x_{1}(r), x_{2}(r)\right)\right|}{\max _{r=1}^{N}\left(x_{1}(r), x_{2}(r)\right)-\min _{r=1}^{N}\left(x_{1}(r), x_{2}(r)\right)}
$$

In Equation (4), the meaning of each symbol is the same as before.

\section{Case Study}

\subsection{Study Area}

The Yellow River is the longest river in north China. The Yellow River basin is an extremely important economic and cultural corridor and natural ecological barrier in China. It contains several basic energy bases and key ecological function areas, and it is also one of the basic water supply sources for northern China, playing an important role in the construction of China's ecological civilization and economic and social development. From the source to the mouth, the Yellow River passes through Qinghai, Sichuan, Gansu, Ningxia, Inner Mongolia, Shaanxi, Shanxi, Henan, and Shandong in turn, called the "nine provinces of the Yellow River basin," hereinafter referred to as the "nine provinces." Most of the nine provinces are arid or semi-arid areas, with a large geographical span and significant differences in altitude. There are large differences in resource and environmental endowments and economic development levels in different provinces and regions, and the difference in per capita GDP between the source and the mouth of the Yellow River is more than 10 times [51]. The elevation distribution of nine provinces of the Yellow River basin is shown in Figure 1. 


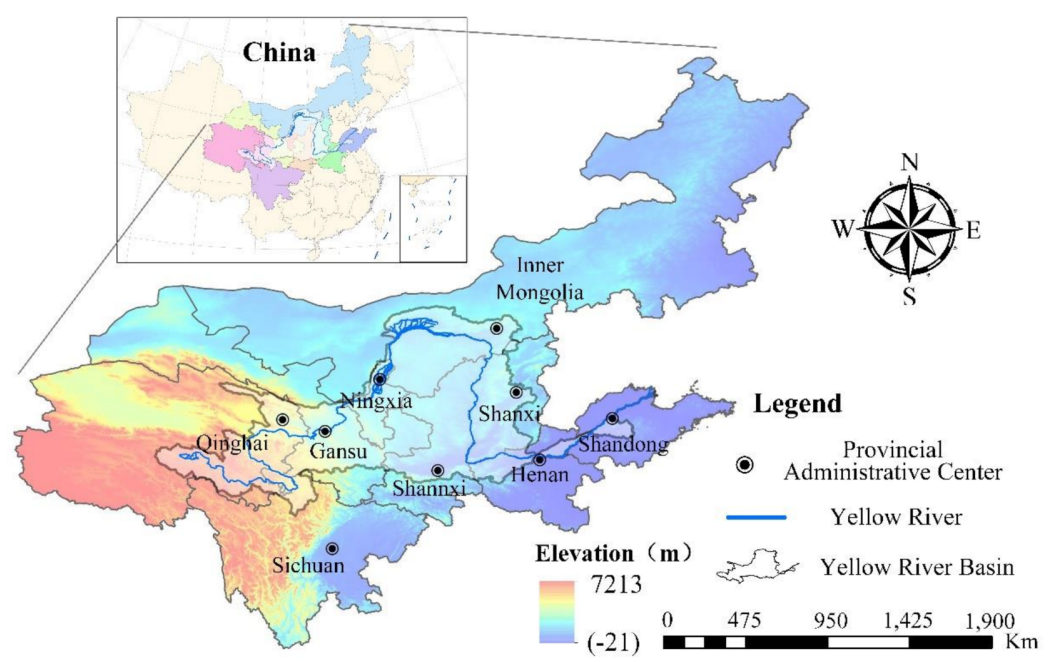

Figure 1. Schematic view of the study area and elevation distribution.

The current situation of economic development of the nine provinces is lower than the overall level of the whole China. According to the "2019 Monitoring Report on China's Cities Completely Built a Well-off Society" issued by the Chinese government, only one of the top 20 prefecture-level cities in the Overall Well-off Index (which can represent the level of economic and social development to some extent) is located in the nine provinces. The nine provinces of the Yellow River Basin account for nearly one-third of the population and $34.8 \%$ of the arable land in China. However, the annual runoff of this river accounts for only $2 \%$ of China's total, with serious water supply and demand conflicts constraining regional development [52]. Especially in the past 20 years, under the general trend of highly rapid economic and social development in China, the water demand of the nine provinces has also increased dramatically. The Yellow River Basin is facing a severe situation of contradiction between water supply and demand. Shrinking natural incoming water and low levels of water utilization are also the causes of water shortages in the basin. The comprehensive improvement of CWUI has significance to the sustainable development of the nine provinces, especially to these provinces in the upper reach.

\subsection{Indicator Description and Data Sources}

When applying the DEA model, the reasonableness of the input-output indicators will directly affect the accuracy of the final efficiency measurement results. Thus, it is very important to construct a comprehensive and effective set of CWUI input-output indicators. The basic idea of efficient utilization of water is to satisfy both minimizations of resource consumption and maximization of production value. Guided by this idea, this study selects four representative indicators from four dimensions of resources, capital, labor, and ecological environment as input variables. The most direct input to reflect the level of water use is water consumption, and the total regional water consumption is used to represent water consumption $[27,30,31,34]$. The level of capital investment is also an important aspect in quantifying the level of resource utilization, using fixed-asset investment to represent social capital investment $[27,29-31,34]$. This study discusses the overall level of regional water utilization. Considering that all industries are inseparable from water utilization, the number of employees is taken as a variable reflecting human resource input [27,29-31]. The water use level without considering environmental pollution cannot reflect the real level of regional water utilization $[30,34]$. In order to evaluate the CWUI of nine provinces in the Yellow River basin more scientifically and comprehensively, this study adds ammonia nitrogen emission in wastewater as an input indicator reflecting environmental pollution. The most intuitive manifestation of a high-level area of water utilization is the ability to obtain higher economic benefits under certain conditions of resource inputs. Therefore, the gross regional product was selected as the output variable reflecting the value of water 
resources production $[27,29-31,34]$. The final input-output indicator selection results are listed in Table 1.

Table 1. Water use level input-output indicator system.

\begin{tabular}{ccc}
\hline Type & Indicators & Necessity \\
\hline & Total water consumption & Reflect natural resource input \\
{$[27,30,31,34]$} & \\
& Reflect social capital input \\
Input indicators & Investment in fixed assets ${ }^{\text {a }}$ & Reflect human capital input \\
& Number of employees & {$[27,29-31]$} \\
& Ammonia nitrogen emissions & Reflect environmental \\
& in wastewater & load-bearing input [30,34] \\
\hline \multirow{2}{*}{ Output indicators } & GDP ${ }^{b}$ & Reflect economic benefit output \\
& & {$[27,29-31,34]$}
\end{tabular}

Notes: ${ }^{a}$ Investment in fixed assets data is processed through the fixed asset investment price index to eliminate price effects. ${ }^{b}$ GDP data are processed through the GDP index to eliminate price effects.

High-quality economic and social development involves economic, social, and ecological aspects. Thus, the level of regional economic and social development needs to be characterized by a combination of indicators. In order to investigate the matching relationship between CWUI and E-SDL in the nine provinces, this study refers to relevant research results [14,50,51], as well as the "Statistical Monitoring Program for Building a Well-off Society" and the "Statistical Monitoring Indicator System for Building a Well-off Society in All Respects" issued by the Chinese government, and follows the principles of representativeness and dynamism to select a total of 12 representative indicators to characterize the relative level of economic and social development in terms of economic development, social harmony, and ecological friendliness. The indicator system is shown in Table 2.

Table 2. Quantitative indicator system of the relative level of economic and social development in nine provinces of the Yellow River Basin.

\begin{tabular}{|c|c|c|c|c|}
\hline Dimensions & Indicators & Characteristic $^{a}$ & Unit & Weight $^{b}$ \\
\hline \multirow{4}{*}{ Economic development } & GDP per capita & + & Yuan RMB & 0.235 \\
\hline & Proportion of R\&D expenditure in GDP & + & $\%$ & 0.078 \\
\hline & $\begin{array}{c}\text { Proportion of added value of tertiary } \\
\text { industry in GDP }\end{array}$ & + & $\%$ & 0.078 \\
\hline & Proportion of urban population & + & $\%$ & 0.098 \\
\hline \multirow{4}{*}{ Social harmony } & $\begin{array}{c}\text { Income ratio between urban and } \\
\text { rural residents }\end{array}$ & - & - & 0.039 \\
\hline & Coverage of basic old-age insurance & + & $\%$ & 0.119 \\
\hline & Disposable income per resident & + & Yuan RMB & 0.119 \\
\hline & $\begin{array}{l}\text { Proportion of residents' entertainment } \\
\text { consumption expenditure }\end{array}$ & + & $\%$ & 0.039 \\
\hline \multirow{4}{*}{ Ecological friendliness } & $\begin{array}{c}\text { Energy consumption per 10,000 Yuan RMB } \\
\text { of GDP }\end{array}$ & - & $\mathrm{t} / 10,000 \mathrm{RMB}$ & 0.078 \\
\hline & Afforestation coverage rate of built-up area & + & $\%$ & 0.039 \\
\hline & Arable land area index & + & $\%$ & 0.039 \\
\hline & Surface water compliance rate & + & $\%$ & 0.039 \\
\hline
\end{tabular}

Notes: ${ }^{\text {a }}$ The " + " in the indicator characteristic represents the "positive indicator," and the larger the value, the stronger the positive effect on E-SDL, and the "-" represents the "negative indicator," and the larger the value, the stronger the negative effect on E-SDL. ${ }^{b}$ The weight of each indicator is combined with the corresponding indicator weights in the "Statistical Monitoring Program for Building a Well-off Society" to be converted to determine.

In order to ensure the reliability of data and the integrity of the time series, a total of seven research years from 2012 to 2018 were finally selected in this study to carry out the 
case study of nine provinces. The raw data used in this study were obtained by collating data from the China Statistical Yearbook, the China Science and Technology Statistical Yearbook, the Water Resources Bulletin of nine provinces, and the Statistical Yearbook of nine provinces.

\section{Results}

\subsection{Spatial-Temporal Evolution Characteristics of Water Use Level}

In this study, the values of CWUI of nine provinces during the period 2012-2018 needed to be dynamically evaluated. When applying the DEA window analysis method, there was no technical progress within a single window because all decision units within each window were involved in the calculation [53]. To increase the credibility of the results, DEA window analysis should be applied with as narrow a window width as possible [54]. Therefore, the optimal window width for the Window-DEA model was determined to be 3 years. The total length of the time series in this study was 7 years, thus for each decision unit, five windows needed to be established, namely Window 1 (2012-2014), Window2 (2013-2015), Window3 (2014-2016), and Window4 (2015-2017), and Window5 (2016-2018). Then the SBM-DEA model was used to measure the CWUI for a total of 27 DMUs in 9 provinces under each window. Using the DEA-SOLVER PRO13.1 software (SAITECH, Tokyo, Japan) [55] based on the EXCEL macro program, the results of the window analysis of the SBM-DEA model for nine provinces during the period 2012-2018 were obtained (Figure 2).
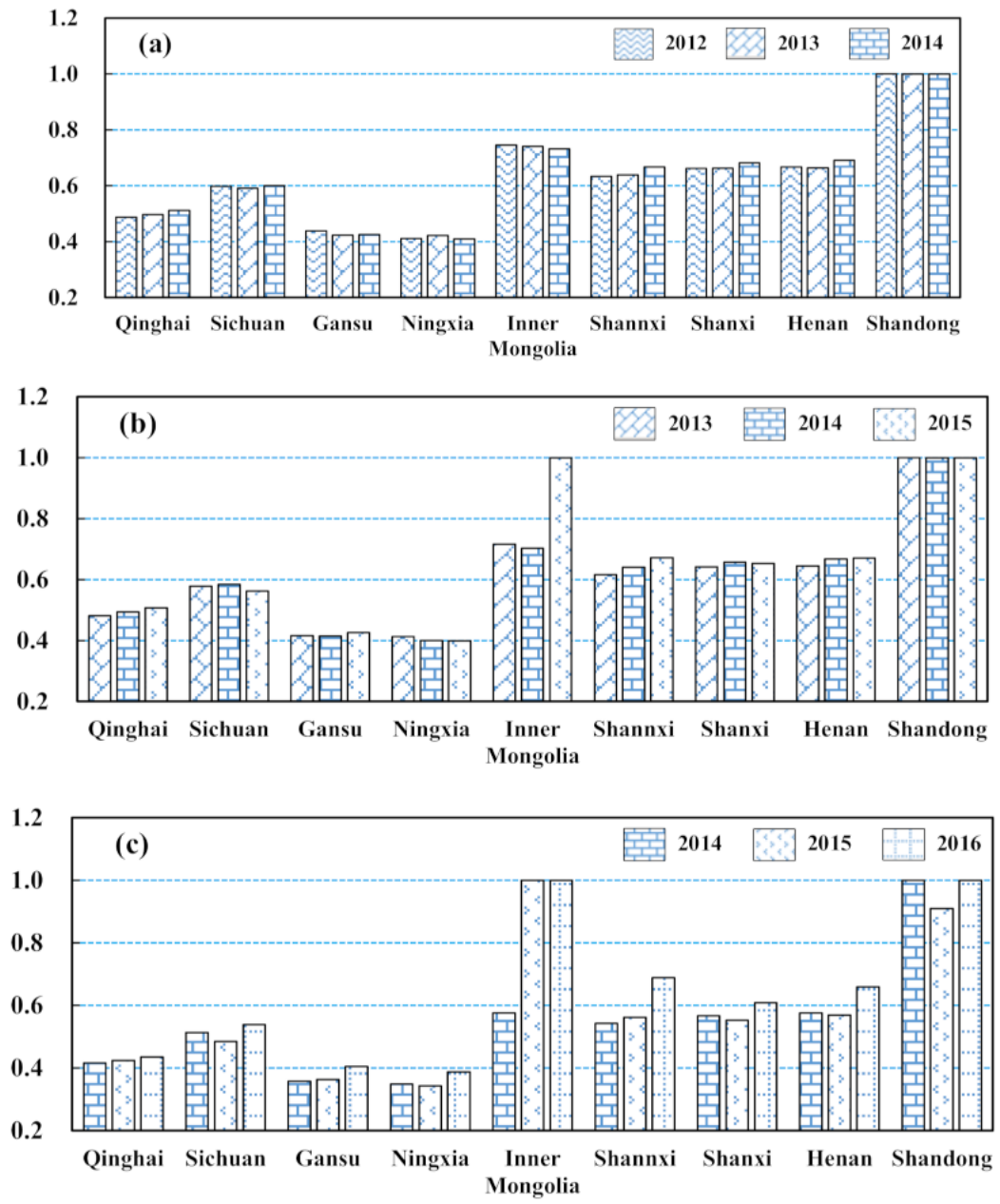

Figure 2. Cont. 

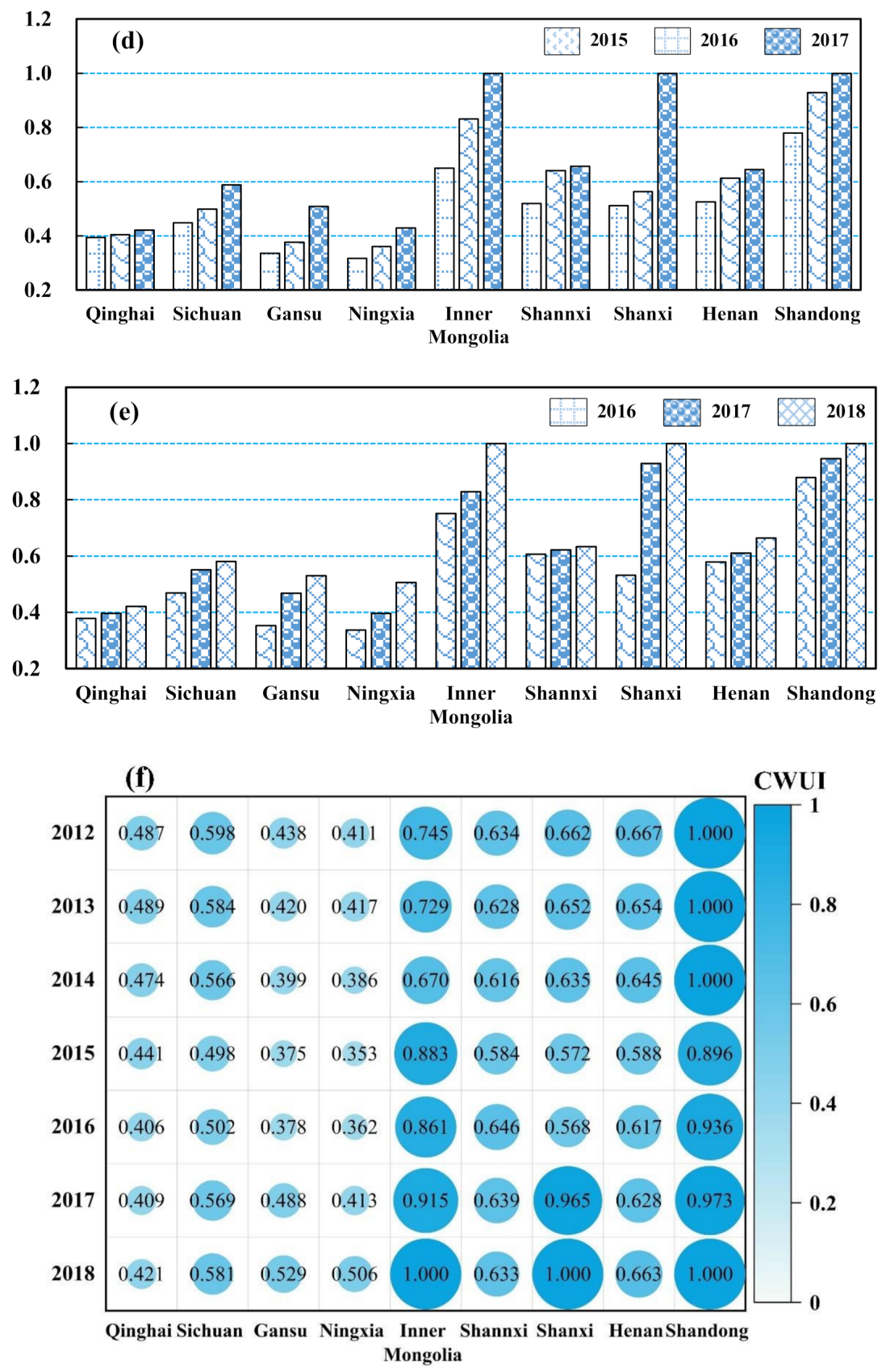

Figure 2. Results of window analysis of SBM-DEA model in nine provinces of the Yellow River Basin. ((a-e) represent Windows 1, Windows 2, Windows 3, Windows 4 and Windows 5, respectively. (f) represents the final result of CWUI of the nine provinces from 2012 to 2018).

As shown in Figure 2, there is an overall decreasing trend in the values for different windows within a given year during the study period. Based on the data distribution characteristics of CWUI, CWUI was classified into five levels of (0-0.5), (0.5-0.7), (0.7-0.8), $(0.8-0.9)$, and (0.9-1.0), representing poor, medium, good, outstanding, and excellent water use levels, respectively. Taking Qinghai province as an example, in 2015, the value under Window2 was 0.506 , CWUI was at a medium level. However, the value under Window3 dropped to 0.425 , and under Window4 its value dropped to 0.394 , under both windows, CWUI was at a poor level. Compared to Window3 and Window4, the CWUI under Window 2 was at a relatively good level, but under Window4, which had a better production frontier, there was a significant decrease in its CWUI value. The CWUI values measured by the data envelopment analysis model were not absolute but were derived by 
comparing the decision-making unit with the production frontier. The CWUI values of the same decision-making unit in the same year can vary depending on the production frontier, thus, the CWUI value has relativity. On the one hand, it shows that the production frontier surface of the nine provinces is moving forward, and the level of water use in the advanced provinces is improving rapidly; on the other hand, it also confirms the relative nature of CWUI values. The results of the window analysis of the SBM-DEA model in Table 3 were compiled to obtain the final results of the CWUI values of the nine provinces from 2012 to 2018, as shown in Figure 2f. The multi-year average values and rankings of CWUI for the nine provinces are listed in Table 3.

Table 3. Multi-year average values and ranking of water use level in nine provinces.

\begin{tabular}{cccccccccc}
\hline Regions & Qinghai & Sichuan & Gansu & Ningxia & $\begin{array}{c}\text { Inner } \\
\text { Mongolia }\end{array}$ & Shannxi & Shanxi & Henan & Shandong \\
\hline Average & 0.447 & 0.557 & 0.433 & 0.407 & 0.829 & 0.626 & 0.722 & 0.637 \\
Rank & 7 & 6 & 8 & 9 & 2 & 5 & 3 & 0.972 \\
\hline
\end{tabular}

From an overall perspective: the overall CWUI values of the nine provinces were above 0.55 from 2012 to 2018, showing a trend of first decreasing and then increasing. The inflection point occurred in 2015, indicating that the overall CWUI level of the nine provinces deviated to the greatest extent from the production frontier surface in 2015, after which the degree of deviation gradually decreased. Subsequently, the CWUI value began to gradually rebound, rising significantly to 0.704 in the three years of 2016-2018, reaching the highest value in the study period.

From the perspective of each province: among the nine provinces, Shandong, Inner Mongolia, and Shanxi had a relatively high level of water utilization, with a multi-year average CWUI above 0.7, at a good level and above. Shandong was the only province that water use was at an excellent level and at a significant advantage in water use level compared to other provinces. Followed by Henan and Shaanxi provinces, with multi-year average CWUI above 0.6 and small fluctuations in CWUI, both provinces were at the medium level. The multi-year average CWUI of Sichuan, Gansu, Qinghai, and Ningxia were all below 0.5 , which deviated from the production frontier surface to a large extent, and the water use level was at a poor level among the nine provinces. During the period 2012-2017, only Shandong province reached the production front surface among the nine provinces, and its CWUI was 1 in 2013, 2014, and 2015, indicating it was the only effective DMU among the nine provinces for three consecutive years. In 2018, the CWUI of Inner Mongolia and Shanxi also exceeded 1 and were jointly located on the production frontier surface with Shandong, while the remaining six provinces failed to reach the production frontier surface during 2012-2018, and the CWUI values of some provinces showed a decreasing trend in multiple years, which to some extent indicates while that the spatial variability of CWUI in the nine provinces of the Yellow River Basin was obvious, the synergy of water use level improvement was poor, and the gap between high and low CWUI provinces is gradually expanding, which is not conducive to the balanced and coordinated development of the nine provinces.

From the perspective of different regions: according to the dividing points of the upper, middle, and lower reaches of the Yellow River, the provinces of Inner Mongolia and above were divided into upstream areas, Shaanxi and Shanxi were divided into midstream areas. In order to facilitate the analysis of regional differences in water use levels in the Yellow River basin, Henan and Shandong were divided into downstream areas in this paper. Finally, the temporal evolution trends of CWUI in different regions are shown in Figure 3. The CWUI evolution trends of upstream and downstream provinces were basically the same, while the CWUI evolution trends of midstream provinces had more obvious fluctuations, and their water utilization levels were significantly improved in multiple years. The spatial distribution characteristics of CWUI in upstream, middle, and downstream provinces were basically consistent with the distribution of their economic and social 
development levels. As can be seen from Figure 3, the CWUI of middle and downstream provinces was higher than that of upstream provinces in all years. Moreover, in 2014, the difference between the CWUI of upstream and downstream provinces reached 0.32 , indicating that the industrial structure of upstream provinces needs to be optimized, there is a large redundancy of resource inputs. There is still a gap between the level of intensive use of water in the upstream provinces and the middle and downstream provinces.

\section{CWUI}

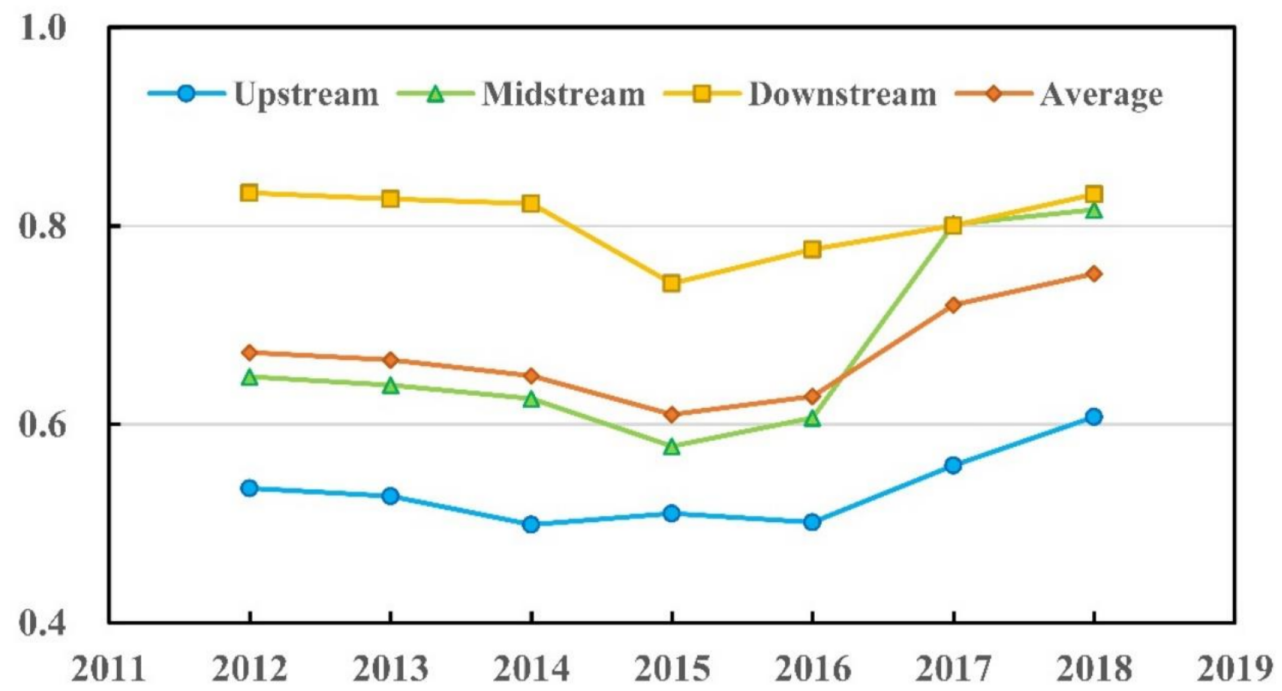

Figure 3. Temporal evolution of CWUI in the upper, middle, and lower provinces, 2012-2018.

\subsection{TFP Analysis of Water Based on Malmquist Index Model}

Based on the panel data of input-output variables of nine provinces from 2012 to 2018, the Malmquist index model was applied to measure the productivity index of nine provinces, and the total factor productivity index and its decomposition result of different years and provinces were obtained, as shown in Table 4 and Figure 4 . The operation was implemented by DEAP2.1 software (Université Laval, Quebec City, Canada) [56].

Table 4. Malmquist Index and its decomposition (average of nine provinces), 2012-2018.

\begin{tabular}{cccccc}
\hline Years & EC & TC & PEC & SEC & MI \\
\hline 2013 & 0.984 & 0.983 & 0.983 & 1.001 & 0.967 \\
2014 & 0.978 & 1.004 & 0.991 & 0.988 & 0.982 \\
2015 & 0.985 & 1.010 & 0.975 & 1.011 & 0.995 \\
2016 & 1.004 & 1.248 & 1.029 & 0.976 & 1.253 \\
2017 & 1.034 & 1.160 & 1.027 & 1.008 & 1.200 \\
2018 & 0.979 & 1.129 & 0.988 & 0.991 & 1.106 \\
Average $^{\text {a }}$ & 0.994 & 1.085 & 0.998 & 0.996 & 1.078
\end{tabular}

Notes: ${ }^{a}$ The multi-year averages of the Malmquist index and each of its decomposition indices are geometric means.

From the results in Table 4, the multi-year average value of MI was 1.078, and MI greater than 1 indicates that the overall TFP of water of the nine provinces showed an increasing trend during the period of 2012-2018. Among them, the overall total factor productivity of water in the nine provinces declined year by year before 2016, but the declining trend gradually leveled off. Moreover, the overall total factor productivity of water has increased year by year since 2016. In order to explore the intrinsic causes of TFP changes, the results of total factor productivity decomposition were further analyzed. Moreover, the multi-year average values of all indices were less than 1, except for technical progress TC, which indicates that technical progress TC was the dominant factor driving TFP improvement. EC was greater than 1 only in 2016 and 2017, indicating that changes 
in integrated technical efficiency only played a driving role in individual years. However, EC, in general, constrains the improvement of total factor productivity of water thus the industrial structure and water resources management mode need to be optimized to improve the scale efficiency and pure technical efficiency of water utilization in the nine provinces.

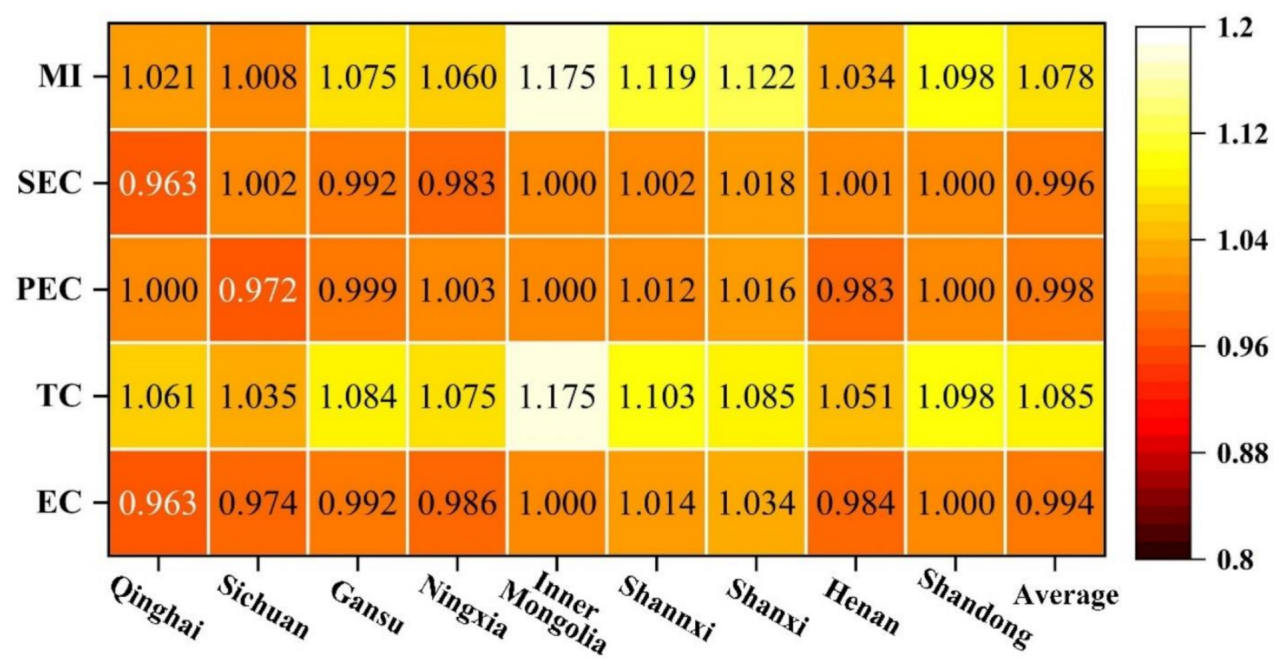

Figure 4. Multi-year average Malmquist index and its decomposition in nine provinces from 2012-2018.

As can be seen from Figure 4, the MI of Inner Mongolia, Shanxi, Shaanxi, and Shandong provinces are all higher than the nine-province average of 1.078 , indicating that the water use level of these four provinces is improving faster. Among them, Inner Mongolia and Shandong provinces, because they are at the production frontier themselves, the improvement of TFP of water is entirely driven by the technological progress TC. In comparison, Shanxi and Shaanxi are driven by both technological progress TC and integrated technical efficiency change EC. The remaining five provinces have been slow to improve their TFP of water, mainly due to the constraints of the integrated technical efficiency change EC, and the distance between their water utilization levels and the production frontier surface has gradually increased. Further decomposition of EC can be found that Qinghai, Gansu, and Ningxia are mainly affected by the scale efficiency change SEC, and the scale efficiency needs to be further optimized, while Sichuan and Henan are mainly constrained by the pure technical efficiency change PEC, and need to focus on strengthening the water resources management level and optimizing the water use structure.

Comparing the Malmquist index and its decomposition results from the perspective of different regions. The comparison of upstream, midstream, and downstream provinces is shown in Figure 5. The overall productivity level of the midstream provinces is higher than that of the upstream and downstream provinces. It is not difficult to find that PEC and SEC of the upstream provinces are both at a lower level, especially the poor performance of SEC, which in turn leads to a much lower integrated technical efficiency change EC than that of the midstream provinces. Thus, the upstream provinces need to reasonably allocate water resources, optimize industrial layout, improve industrial concentration, and narrow the gap between their SEC and that of the midstream and downstream provinces. Technological progress TC is the main driving force of TFP of water in the three regions, and the difference of TC in the three regions is relatively small, with the upstream provinces even slightly higher than the downstream provinces. The production frontier of each of the three regions has moved forward significantly, indicating that the nine provinces have all invested more in scientific research in the field of efficient water utilization in recent years, effectively promoting the transformation of advanced technology into productivity [57]. 


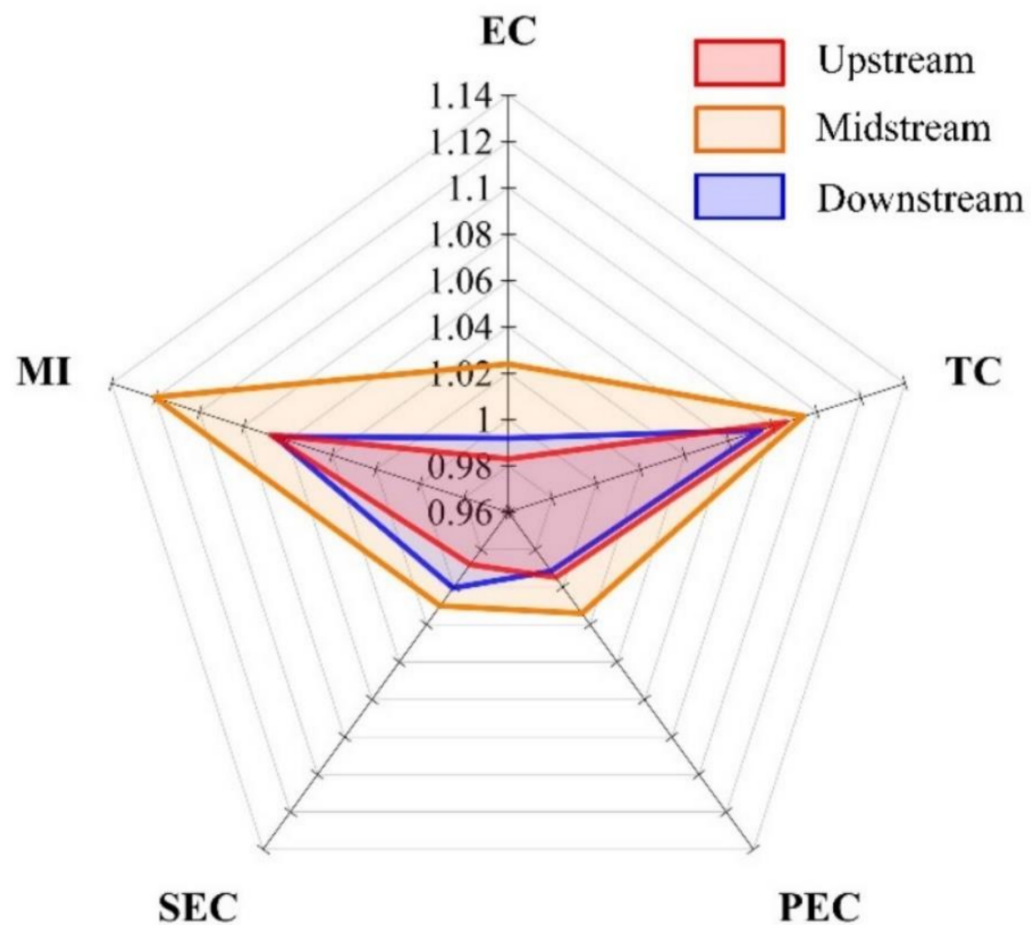

Figure 5. Comparison of the multi-year average Malmquist index and its decomposition in the upstream, midstream, and downstream provinces.

\subsection{Matching Relationship between CWUI and E-SDL}

\subsubsection{Analysis of the Relative Level of Economic-Social Development}

Based on the quantitative index system of the relative level of economic and social development in the nine provinces in Table 2, the data of each index in the nine provinces during the period of 2012-2018 were normalized, and then all the indexes were weighted and summed up by combining the weights to obtain the quantitative characterization value of E-SDL. Arcgis10.2 software was used to map the E-SDL calculation results of the nine provinces for multiple years into a spatial distribution map, which was used to characterize the spatial and temporal distribution characteristics of the economic and social development levels of the nine provinces, as shown in Figure 6. On the time scale, the average value of E-SDL in the nine provinces showed an increasing yearly trend during the seven years, from 0.352 in 2012 to 0.657 in 2018, indicating that with the gradual implementation of the concept of sustainable and green development, the overall level of economic and social development in the nine provinces is continuously improving. Gansu, Qinghai, Sichuan, and Henan, have seen the fastest improvement in economic and social development, with E-SDL more than doubling in seven years. From the three criteria, it was found that the economic development and social harmony of the above four provinces rapidly improved in the past seven years under the premise of maintaining the steady growth of the level of ecological friendliness, thus realizing the obvious improvement of E-SDL. On the spatial scale, there were large spatial differences in the economic and social development levels of the nine provinces. In terms of the multi-year average value of E-SDL, the economic and social development level of Shandong was relatively high (E-SDL > 0.7), the E-SDLs of Inner Mongolia, Shaanxi, Henan, Sichuan, Shanxi, and Ningxia were at an intermediate level $(0.4<$ E-SDL $<0.6)$, and the economic and social development levels of Gansu and Qinghai were low $(\mathrm{E}-\mathrm{SDL}<0.4)$. The E-SDL of the nine provinces as a whole shows the spatial distribution characteristics of downstream, midstream, and upstream provinces in descending order, which is basically consistent with the regional step structure of economic and social development in the Yellow River basin [14]. 

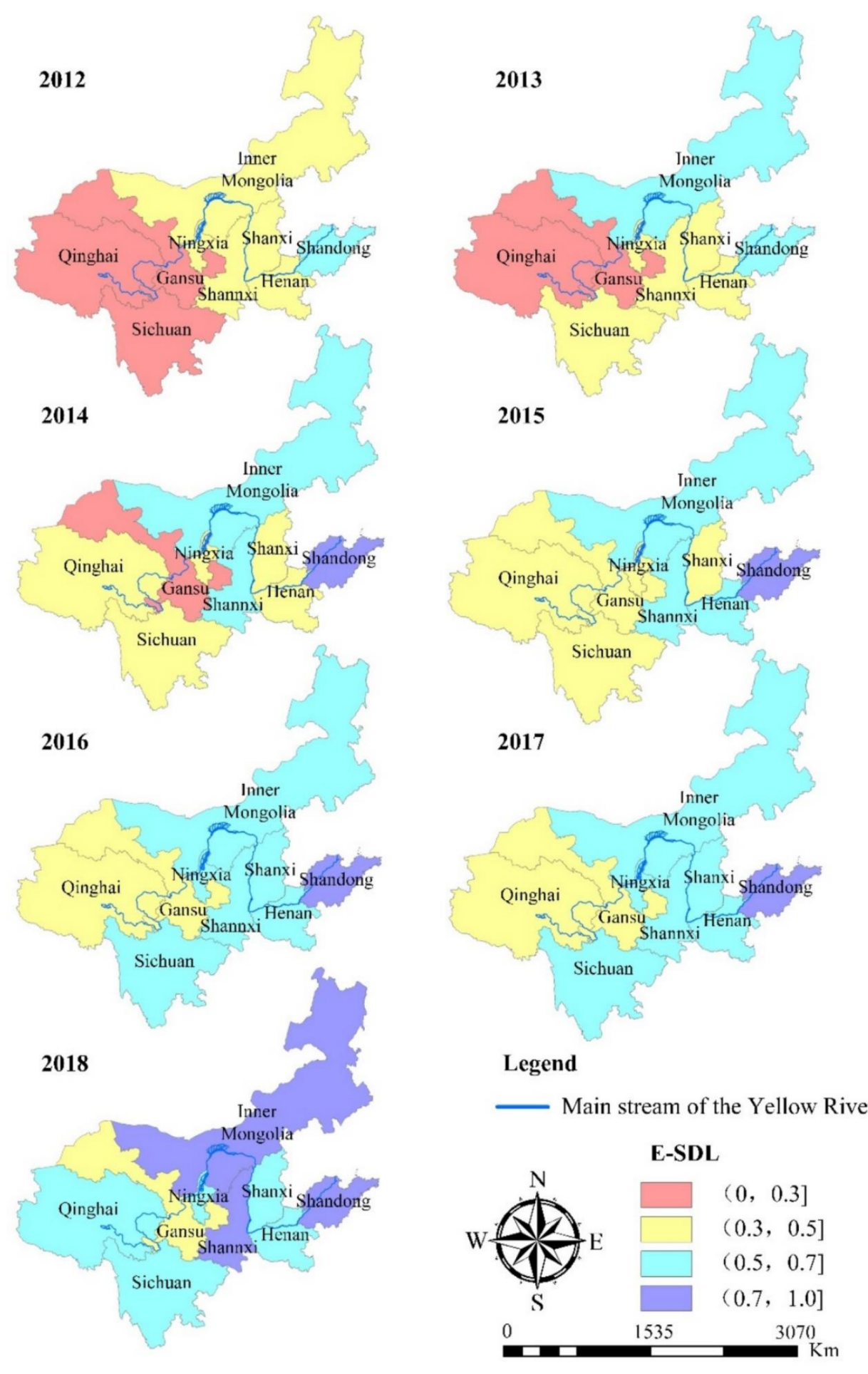

Figure 6. Spatial and temporal distribution characteristics of E-SDL in nine provinces from 2012 to 2018.

\subsubsection{Analysis of Matching Degree between CWUI and E-SDL}

The spatial matching degree of the multi-year average CWUI and E-SDL of nine provinces was calculated using the spatial matching degree calculation method based on the series distance, and the results are shown in Figure 7. To further analyze the temporal change characteristics of the matching degree, the spatial matching degree of CWUI and E-SDL of the nine provinces and the upstream, midstream, and downstream provinces of the Yellow River in 2012, 2015, and 2018 were measured, and the results are listed in Table 5. 


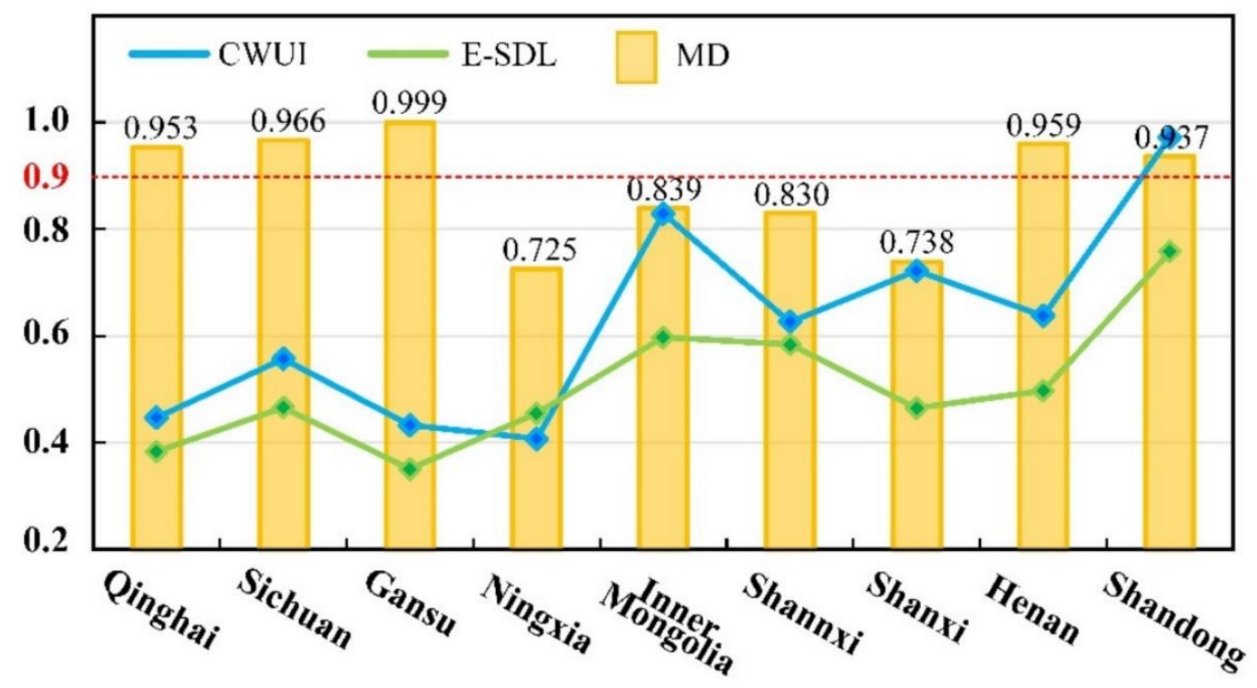

Figure 7. Matching characteristics of multi-year average CWUI and E-SDL in nine provinces (The red dash line can be used as an auxiliary line to identify provinces with high matching degrees).

Table 5. The spatial matching degree between CWUI and E-SDL in nine provinces in 2012, 2015, and 2018.

\begin{tabular}{cccccccccc}
\hline \multirow{2}{*}{ Regions } & \multicolumn{3}{c}{$\mathbf{2 0 1 2}$} & & $\mathbf{2 0 1 5}$ & & \multicolumn{2}{c}{$\mathbf{2 0 1 8}$} \\
\cline { 2 - 9 } & CWUI & E-SDL & MD & CWUI & E-SDL & MD & CWUI & E-SDL & MD \\
\hline Qinghai & 0.487 & 0.225 & 0.875 & 0.441 & 0.373 & 0.972 & 0.421 & 0.550 & 0.710 \\
Sichuan & 0.598 & 0.287 & 0.871 & 0.498 & 0.456 & 0.958 & 0.581 & 0.673 & 0.757 \\
Gansu & 0.438 & 0.202 & 0.885 & 0.375 & 0.347 & 0.960 & 0.529 & 0.499 & 0.990 \\
Ningxia & 0.411 & 0.322 & 0.761 & 0.353 & 0.430 & 0.746 & 0.506 & 0.619 & 0.729 \\
Inner Mongolia & 0.745 & 0.461 & 0.889 & 0.883 & 0.600 & 0.635 & 1.000 & 0.718 & 0.602 \\
Shannxi & 0.634 & 0.430 & 0.808 & 0.584 & 0.576 & 0.864 & 0.633 & 0.750 & 0.705 \\
Shanxi & 0.662 & 0.325 & 0.879 & 0.572 & 0.484 & 0.965 & 1.000 & 0.580 & 0.346 \\
Henan & 0.667 & 0.331 & 0.888 & 0.588 & 0.500 & 0.969 & 0.663 & 0.665 & 0.916 \\
Shandong & 1.000 & 0.585 & 0.939 & 0.896 & 0.779 & 0.988 & 1.000 & 0.858 & 0.860 \\
Upstream & 0.536 & 0.299 & 0.987 & 0.510 & 0.441 & 0.963 & 0.608 & 0.612 & 0.703 \\
Midstream & 0.648 & 0.377 & 0.924 & 0.578 & 0.530 & 0.899 & 0.816 & 0.665 & 0.658 \\
Downstream & 0.833 & 0.458 & 0.936 & 0.742 & 0.640 & 0.936 & 0.832 & 0.761 & 0.954 \\
\hline
\end{tabular}

From the results in Figure 7, the CWUI of Gansu, Sichuan, Henan, Qinghai, and Shandong matches well with the E-SDL (MD > 0.9), but the matching categories in different provinces are not exactly the same. Shandong and Henan provinces have a high level of economic and social development, and their water use level is relatively good among the nine provinces, which is a "high-high" match. Gansu and Qinghai provinces have a relatively low level of economic and social development, and their CWUI is also at the back of the nine provinces, which is a "low-low" match. The degree of matching CWUI with the E-SDL in Inner Mongolia and Shaanxi provinces is medium among the nine provinces $(0.8<\mathrm{MD}<0.9)$. The match between CWUI and E-SDL in Ningxia and Shanxi provinces is poor $(\mathrm{MD}<0.8)$, and the reason for this is that Shanxi Province has a high CWUI among the nine provinces, while the level of economic and social development is relatively low, resulting in the two not matching in value. Ningxia, however, is at the bottom of the nine provinces in terms of water use level, but its economic and social development is at the middle level among the nine provinces, and it needs to focus on improving water resources utilization in the future economic and social development process. In another study on the coordination between water use and urbanization [58], the results show that there are significant differences in the synergistic effects between water use level and urbanization in different provinces in China. Moreover, the differences can be divided into three different 
types of synergy, with only individual provinces showing a significant synergistic effect of urbanization level on water use. The results are similar to those of this paper, and to a certain extent, they verify the spatial variability of CWUI and E-SDL among nine provinces in the Yellow River basin.

From the results in Table 5, the matching degree of CWUI and E-SDL in Gansu Province has been increasing within the three study years of 2012, 2015, and 2018, and its MD has increased from 0.885 in 2012 to 0.990 in 2018. The matching degree of water use level and economic and social development level in Gansu Province in 2018 is the highest among the nine provinces, but it belongs to the "low-low" matching type, which still needs to improve CWUI and E-SDL comprehensively. The match between CWUI and E-SDL in Ningxia and Inner Mongolia provinces has been decreasing, with MD in Ningxia decreasing from 0.761 in 2012 to 0.729 in 2018 and MD in Inner Mongolia decreasing from 0.889 in 2012 to 0.602 in 2018. It indicates that compared with other provinces, the synergy between the level of water utilization and the improvement of economic and social development level in these two provinces is poor, and should focus on the coordinated and harmonious development of water resources utilization and economy and society. The main problem in Ningxia is the low level of water utilization, and the level of water utilization in Inner Mongolia is at a high level, but its economic and social development level is not outstanding, and it needs to pay attention to the all-round balanced development of economy, society, resources, and ecology.

The MD of the six provinces of Qinghai, Sichuan, Henan, Shaanxi, Shandong, and Shanxi showed the characteristics of first rising and then falling within three years. CWUI and E-SDL reached the best matching status in 2015. Among the six provinces mentioned above, the characteristics of MD changes can be explained in three cases. The first case is that the improvement of water use level lags behind the improvement of economic and social development level, such as Sichuan, Shaanxi, and Qinghai provinces. Sichuan's CWUI was ranked 6th in all three years 2012, 2015, and 2018, but its E-SDL improved significantly from 7th in 2012 to 4th in 2018. Shaanxi's CWUI ranked 5th in 2012 and 2018 and 4th in 2015, but its economic and social development level improved from 3rd in 2012 to 2nd in 2018. Qinghai's CWUI dropped from the 7th in 2012 to the 9th in 2018, and its E-SDL remained at the 8th for three years. The second case is that the E-SDL is rising faster, but the level of water utilization is rising slower, such as Shanxi Province. Its CWUI rose from 4th in 2012 to 2nd in 2018, but its E-SDL dropped from 5th in 2012 to 7th in 2018. The third case is that the level of water utilization and the level of economic and social development has maintained simultaneous improvement to some extent, such as Henan and Shandong. Henan's CWUI decreased from 3rd in 2012 to 4th in 2018, and its E-SDL decreased from 4th in 2012 to 5th in 2018. CWUI and E-SDL of Shandong Province have maintained 1st place in 2012, 2015, and 2018, and although there are fluctuations in $\mathrm{MD}$, the fluctuations are not obvious, and the water use level and economic and social development level have maintained a relatively coordinated development. Analyzed from the perspective of different regions in the Yellow River Basin, the overall situation is that the MD of downstream provinces is higher than that of upstream provinces than that of midstream provinces. Except for the downstream provinces, the MDs of the remaining two regions showed a decreasing trend year by year during 2012, 2015, and 2018, and their economic and social development and water use level failed to achieve a harmonious and balanced improvement, and the upstream and midstream provinces of the Yellow River Basin still need to focus on the simultaneous improvement of water use level under the premise of ensuring economic and social development.

\section{Conclusions}

Based on the SBM-DEA model and combined with the Window-DEA model, this study measured the water use level of nine provinces in the Yellow River Basin from 2012 to 2018 and decomposed the TFP changes of water in the nine provinces using the Malmquist index model. A quantitative index system of economic and social development levels 
was constructed, the spatial and temporal variation characteristics of the relative levels of economic and social development in the nine provinces were analyzed, and finally the matching relationship between water use level and economic and social development levels in the nine provinces of the Yellow River Basin was explored. The results were concluded as follows:

(1) The nine provinces showed an overall increasing trend in water use level during 2012-2018, with the midstream and downstream provinces having higher overall water use levels than the upstream provinces. The water use level of Shandong Province was at the production frontier of the nine provinces for a long time, and the gap between the water use levels of different provinces is gradually expanding. The upstream and midstream provinces of the Yellow River Basin should optimize the water resources utilization pattern, combine the advanced experience of water resources utilization in Shandong Province, and explore the effective ways to improve the level of regional water resources utilization according to local conditions. Efforts should be made to narrow the gap between water use level and that of downstream provinces.

(2) Technological progress TC is the dominant factor driving the TFP of water in the nine provinces, and integrated technical efficiency change EC overall constrains the TFP of water. Insufficient SEC and PEC are the main reasons for the productivity level gap between upstream and downstream provinces and midstream provinces. The relevant departments of water resources management in the Yellow River Basin should strengthen the implementation of the most stringent water resources management system. While ensuring technological progress, relevant departments should strengthen the level of water resources management, promote the adjustment of its industrial structure in areas lagging behind in water utilization, and force the improvement of comprehensive technical efficiency of regional water resources utilization.

(3) There are significant regional differences in the match between the level of economic and social development and the level of water utilization in the nine provinces, with Gansu, Sichuan, Henan, Qinghai, and Shandong having a better match, but with different match types. Among them, Gansu and Qinghai belong to the "low-low" matching type, which needs to improve both the level of water utilization and the level of economic and social development. The matching degree of CWUI and ESDL in Ningxia and Shanxi is poor, and there is no dynamic synergy between the improvement of economic and social development level and the improvement of water use level. The harmonious relationship between resource utilization and economic and social development is an important foundation for regional sustainability. Moreover, the nine provinces in the Yellow River Basin should explore new paths for high-quality development based on a harmonious balance between the two.

The findings of the study clarify the characteristics of temporal changes and spatial distribution patterns of water use levels in the nine provinces of the Yellow River Basin in recent years. The key factors leading to the variation of total factor productivity of water resources in the nine provinces are also identified, and the results of the study can provide some basis for the strictest water resources management in different regions of the Yellow River Basin. In addition, this paper analyzes the adaptation characteristics between water resources utilization and economic and social development in the nine provinces, which can provide some reference for the future high-quality development layout of the Yellow River basin to a certain extent. It is also a useful exploration to carry out more complex research on the relationship between water resources utilization and economic and social development in the future.

Despite that, limitations also exist in the present study, which could be further improved. First, the SBM-DEA model cannot allow further comparison of the CWUI values of multiple effective DMUs. For example, in 2018, we learned that the CWUI of Inner Mongolia, Shanxi, and Shandong are all one, but we cannot make further comparisons of the three levels. A possible solution to this problem is to explore the applicability of more comprehensive DEA models (e.g., super-efficient SBM-DEA models) in water use 
level studies. Second, the water use level involves many aspects such as resources, ecology, economy, and society, etc. Although the input-output index system of water use level constructed in this study covers as many representative indicators as possible, the extent to which it can represent the real level of water utilization still needs to be further explored. Third, this study explores the spatial matching characteristics between CWUI and E-SDL using the method of calculating spatial matching based on the series distance. However, this method cannot explore the degree of coordination of different variables on the time series. In future research, a combination of multiple coordination relationship exploration methods (e.g., Tapio decoupling model, coupling coordination degree model) can be used to comprehensively explore the adaptation relationship between CWUI and E-SDL in both time and space dimensions.

Author Contributions: Conceptualization, formal analysis, funding acquisition and project administration, Q.Z.; data curation, methodology, software, visualization, writing —original draft, Z.Z.; investigation, L.J. and J.M.; supervision, Q.Z. and J.M.; resources, W.Z. and H.C.; writing-review and editing, Q.Z., L.J., J.M., W.Z. and H.C. All authors have read and agreed to the published version of the manuscript.

Funding: This research was funded by the National Key Research and Development Program of China (No. 2021YFC3200201) and the Major Science and Technology Projects for Public Welfare of Henan Province (No. 201300311500).

Data Availability Statement: Publicly available datasets were analyzed in this study. This data can be found here: [http://www.stats.gov.cn/tjsj/ndsj/].

Acknowledgments: The authors are grateful to the editors and the anonymous reviewers for their insightful comments and helpful suggestions.

Conflicts of Interest: The authors declare no conflict of interest.

\section{References}

1. Nordstrom, D.K. Worldwide occurrences of arsenic in ground water. Science 2002, 296, 2143-2145. [CrossRef]

2. Zuo, Q.; Diao, Y.; Hao, L.; Han, C. Comprehensive evaluation of the human-water harmony relationship in countries along the "belt and road". Water Resour. Manag. 2020, 34, 4019-4035. [CrossRef]

3. Pereira, L.S.; Cordery, I.; Iacovides, I. Improved indicators of water use performance and productivity for sustainable water conservation and saving. Agric. Water Manag. 2012, 108, 39-51. [CrossRef]

4. Pizzi, S.; Caputo, A.; Corvino, A.; Venturelli, A. Management research and the UN sustainable development goals (SDGs): A bibliometric investigation and systematic review. J. Clean Prod. 2020, 276, 124033. [CrossRef]

5. Queiroz, V.C.; de Carvalho, R.C.; Heller, L. New approaches to monitor inequalities in access to water and sanitation: The SDGs in Latin America and the Caribbean. Water 2020, 12, 931. [CrossRef]

6. Hellegers, P.; van Halsema, G. SDG indicator 6.4. 1 "change in water use efficiency over time": Methodological flaws and suggestions for improvement. Sci. Total Environ. 2021, 801, 149431. [CrossRef] [PubMed]

7. Keesstra, S.; Mol, G.; De Leeuw, J.; Okx, J.; De Cleen, M.; Visser, S. Soil-related sustainable development goals: Four concepts to make land degradation neutrality and restoration work. Land 2018, 7, 133. [CrossRef]

8. Zuo, Q.; Li, X.; Hao, L.; Hao, M. Spatiotemporal Evolution of Land-Use and Ecosystem Services Valuation in the Belt and Road Initiative. Sustainability 2020, 12, 6583. [CrossRef]

9. Zakari, A.; Khan, I.; Tan, D.; Alvarado, R.; Dagar, V. Energy efficiency and sustainable development goals (SDGs). Energy 2022, 239, 122365. [CrossRef]

10. Piao, S.; Ciais, P.; Huang, Y.; Shen, Z.; Peng, S.; Li, J.; Zhou, L.; Liu, H.; Ma, Y.; Ding, Y. The impacts of climate change on water resources and agriculture in China. Nature 2010, 467, 43-51. [CrossRef] [PubMed]

11. Yu, Y.; Yang, X.; Li, K. Effects of the terms and characteristics of cadres on environmental pollution: Evidence from 230 cities in China. J. Environ. Manag. 2019, 232, 179-187. [CrossRef] [PubMed]

12. Luo, Z.; Shao, Q.; Zuo, Q.; Cui, Y. Impact of land use and urbanization on river water quality and ecology in a dam dominated basin. J. Hydrol. 2020, 584, 124655. [CrossRef]

13. Zuo, Q.; Jin, R.; Ma, J.; Cui, G. China pursues a strict water resources management system. Environ. Earth Sci. 2014, 72, $2219-2222$. [CrossRef]

14. Jiang, L.; Zuo, Q.; Ma, J.; Zhang, Z. Evaluation and prediction of the level of high-quality development: A case study of the Yellow River Basin, China. Ecol. Indic. 2021, 129, 107994. [CrossRef]

15. Xi, J. Speech at the symposium on ecological protection and high-quality development of the Yellow River Basin. China Water Resour. 2019, 20,1-3. 
16. Katerji, N.; Mastrorilli, M.; Rana, G. Water use efficiency of crops cultivated in the Mediterranean region: Review and analysis. Eur. J. Agron. 2008, 28, 493-507. [CrossRef]

17. Ullah, H.; Santiago-Arenas, R.; Ferdous, Z.; Attia, A.; Datta, A. Improving water use efficiency, nitrogen use efficiency, and radiation use efficiency in field crops under drought stress: A review. Adv. Agron. 2019, 156, 109-157.

18. Koech, R.; Langat, P. Improving irrigation water use efficiency: A review of advances, challenges and opportunities in the Australian context. Water 2018, 10, 1771. [CrossRef]

19. Aller, D.; Rathke, S.; Laird, D.; Cruse, R.; Hatfield, J. Impacts of fresh and aged biochars on plant available water and water use efficiency. Geoderma 2017, 307, 114-121. [CrossRef]

20. Khayyam, S.; Mashal, M.; Aliniaeifard, S.; Varavipour, M. Determination of water use efficiency and water-nitrogen production function for Radish crop. Water Irrig. Manag. 2021, 11, 315-324.

21. Li, H.; Zhao, F.; Li, C.; Yi, Y.; Bu, J.; Wang, X.; Liu, Q.; Shu, A. An improved ecological footprint method for water resources utilization assessment in the cities. Water 2020, 12, 503. [CrossRef]

22. Wang, G.; Xiao, C.; Qi, Z.; Meng, F.; Liang, X. Development tendency analysis for the water resource carrying capacity based on system dynamics model and the improved fuzzy comprehensive evaluation method in the Changchun city, China. Ecol. Indic. 2021, 122, 107232. [CrossRef]

23. Wang, S.; Zhou, L.; Wang, H.; Li, X. Water use efficiency and its influencing factors in China: Based on the Data Envelopment Analysis (DEA)-Tobit Model. Water 2018, 10, 832. [CrossRef]

24. Wang, F.; Yu, C.; Xiong, L.; Chang, Y. How can agricultural water use efficiency be promoted in China? A spatial-temporal analysis. Resour. Conserv. Recycl. 2019, 145, 411-418. [CrossRef]

25. Zhang, W.; Du, X.; Huang, A.; Yin, H. Analysis and comprehensive evaluation of water use efficiency in China. Water 2019, 11, 2620. [CrossRef]

26. Ibrahim, M.D.; Ferreira, D.C.; Daneshvar, S.; Marques, R.C. Transnational resource generativity: Efficiency analysis and target setting of water, energy, land, and food nexus for OECD countries. Sci. Total Environ. 2019, 697, 134017. [CrossRef] [PubMed]

27. Deng, G.; Li, L.; Song, Y. Provincial water use efficiency measurement and factor analysis in China: Based on SBM-DEA model Ecol. Indic. 2016, 69, 12-18. [CrossRef]

28. Lu, W.; Liu, W.; Hou, M.; Deng, Y.; Deng, Y.; Zhou, B.; Zhao, K. Spatial-Temporal Evolution Characteristics and Influencing Factors of Agricultural Water Use Efficiency in Northwest China-Based on a Super-DEA Model and a Spatial Panel Econometric Model. Water 2021, 13, 632. [CrossRef]

29. Yang, W.; Li, L. Analysis of total factor efficiency of water resource and energy in China: A study based on DEA-SBM model. Sustainability 2017, 9, 1316. [CrossRef]

30. Yang, G.-1.; Yang, D.-G. Investigating industrial water-use efficiency in mainland China: An improved SBM-DEA model. $J$. Environ. Manag. 2020, 270, 110859.

31. Yang, G.-1.; Yang, D.-G. Industrial water-use efficiency in China: Regional heterogeneity and incentives identification. J. Clean Prod. 2020, 258, 120828.

32. Sun, B.; Yang, X.; Zhang, Y.; Chen, X. Evaluation of water use efficiency of 31 provinces and municipalities in China using multi-level entropy weight method synthesized indexes and data envelopment analysis. Sustainability 2019, 11, 4556. [CrossRef]

33. Geng, Q.; Ren, Q.; Nolan, R.H.; Wu, P.; Yu, Q. Assessing China's agricultural water use efficiency in a green-blue water perspective: A study based on data envelopment analysis. Ecol. Indic. 2019, 96, 329-335. [CrossRef]

34. Hu, Z.; Yan, S.; Yao, L.; Moudi, M. Efficiency evaluation with feedback for regional water use and wastewater treatment. J. Hydrol. 2018, 562, 703-711. [CrossRef]

35. Zhou, X.; Luo, R.; Yao, L.; Cao, S.; Wang, S.; Lev, B. Assessing integrated water use and wastewater treatment systems in China: A mixed network structure two-stage SBM DEA model. J. Clean Prod. 2018, 185, 533-546. [CrossRef]

36. Bai, M.; Zhou, S.; Zhao, M.; Yu, J. Water use efficiency improvement against a backdrop of expanding city agglomeration in developing countries-A case study on industrial and agricultural water use in the Bohai Bay Region of China. Water 2017, 9, 89. [CrossRef]

37. Mohsin, M.; Abbas, Q.; Zhang, J.; Ikram, M.; Iqbal, N. Integrated effect of energy consumption, economic development, and population growth on CO 2 based environmental degradation: A case of transport sector. Environ. Sci. Pollut. Res. 2019, 26, 32824-32835. [CrossRef] [PubMed]

38. Sarkodie, S.A.; Strezov, V. Effect of foreign direct investments, economic development and energy consumption on greenhouse gas emissions in developing countries. Sci. Total Environ. 2019, 646, 862-871. [CrossRef]

39. Raza, S.A.; Shah, N.; Sharif, A. Time frequency relationship between energy consumption, economic growth and environmental degradation in the United States: Evidence from transportation sector. Energy 2019, 173, 706-720. [CrossRef]

40. Lu, Z.-N.; Chen, H.; Hao, Y.; Wang, J.; Song, X.; Mok, T.M. The dynamic relationship between environmental pollution, economic development and public health: Evidence from China. J. Clean Prod. 2017, 166, 134-147. [CrossRef]

41. Shu, C.; Xie, H.; Jiang, J.; Chen, Q. Is urban land development driven by economic development or fiscal revenue stimuli in China? Land Use Policy 2018, 77, 107-115. [CrossRef]

42. Cheng, X.; Chen, L.; Sun, R.; Kong, P. Land use changes and socio-economic development strongly deteriorate river ecosystem health in one of the largest basins in China. Sci. Total Environ. 2018, 616, 376-385. [CrossRef]

43. Zhongming, Z.; Wangqiang, Z.; Wei, L. UN World Water Development Report 2021 'Valuing Water'; UNESCO: Paris, France, 2021. 
44. Sun, Y.; Liu, N.; Shang, J.; Zhang, J. Sustainable utilization of water resources in China: A system dynamics model. J. Clean Prod. 2017, 142, 613-625. [CrossRef]

45. Huang, Y.; Huang, X.; Xie, M.; Cheng, W.; Shu, Q. A study on the effects of regional differences on agricultural water resource utilization efficiency using super-efficiency SBM model. Sci. Rep. 2021, 11, 9953. [CrossRef]

46. Tone, K. A slacks-based measure of efficiency in data envelopment analysis. Eur. J. Oper. Res. 2001, 130, 498-509. [CrossRef]

47. Charnes, A.; Clark, C.T.; Cooper, W.W.; Golany, B. A Developmental Study of Data Envelopment Analysis in Measuring the Efficiency of Maintenance Units in the US Air Forces; Center for Cybernetic Studies, University of Texas: Austin, TX, USA, 1983.

48. Caves, D.W.; Christensen, L.R.; Diewert, W.E. Multilateral comparisons of output, input, and productivity using superlative index numbers. Econ. J. 1982, 92, 73-86. [CrossRef]

49. Färe, R.; Grosskopf, S.; Norris, M.; Zhang, Z. Productivity growth, technical progress, and efficiency change in industrialized countries. Am. Econ. Rev. 1994, 84, 66-83.

50. Zuo, Q.; Zhao, H.; Ma, J.; Zhang, C. Calculation method and application of matching degree between water resources utilization and economic and social development. Adv. Sci. Technol. Water Resour. 2014, 34, 1-6.

51. Zuo, Q.; Hao, M.; Zhang, Z.; Jiang, L. Assessment of the happy river index as an integrated index of river health and human well-being: A case study of the Yellow River, China. Water 2020, 12, 3064. [CrossRef]

52. Qiu, M.; Yang, Z.; Zuo, Q.; Wu, Q.; Jiang, L.; Zhang, Z.; Zhang, J. Evaluation on the relevance of regional urbanization and ecological security in the nine provinces along the Yellow River, China. Ecol. Indic. 2021, 132, 108346. [CrossRef]

53. Asmild, M.; Paradi, J.C.; Aggarwall, V.; Schaffnit, C. Combining DEA window analysis with the Malmquist index approach in a study of the Canadian banking industry. J. Product. Anal. 2004, 21, 67-89. [CrossRef]

54. Halkos, G.E.; Tzeremes, N.G. Exploring the existence of Kuznets curve in countries' environmental efficiency using DEA window analysis. Ecol. Econ. 2009, 68, 2168-2176. [CrossRef]

55. DEA-SOLVER PRO, Research Software, Version 13.1.; SAITECH: Tokyo, Japan. Available online: http:/ / www.saitech-inc.com/ Products/Prod-DSP.asp(accessed on 15 June 2021).

56. DEAP, Research Software, Version 2.1.; Université Laval: Quebec City, Canada. Available online: https://pypi.org/project/ deap/(accessed on 17 June 2021).

57. Chen, Y.; Zhu, M.; Lu, J.; Zhou, Q.; Ma, W. Evaluation of ecological city and analysis of obstacle factors under the background of high-quality development: Taking cities in the Yellow River Basin as examples. Ecol. Indic. 2020, 118, 106771. [CrossRef]

58. Wang, S.Y.; Chen, W.M.; Wang, R.; Zhao, T. Study on the coordinated development of urbanization and water resources utilization efficiency in China. Water Supply 2021, 22, 749-765. [CrossRef] 